\title{
Saint-Astier - Le Roudier-Ouest
}

\section{Marc Rimé}

URL : http://journals.openedition.org/adlfi/7854

ISSN : 2114-0502

Éditeur

Ministère de la culture

Référence électronique

Marc Rimé, "Saint-Astier - Le Roudier-Ouest », ADLFI. Archéologie de la France - Informations [En ligne], Aquitaine, mis en ligne le 01 mars 2007, consulté le 01 mai 2019. URL : http://

journals.openedition.org/adlfi/7854

Ce document a été généré automatiquement le 1 mai 2019.

(c) Ministère de la Culture et de la Communication, CNRS 


\title{
Saint-Astier - Le Roudier-Ouest
}

\author{
Marc Rimé
}

Identifiant de l'opération archéologique : 025200

Date de l'opération : 2007 (EX)

1 Dans le cadre d'un projet de construction d'un bâtiment industriel et ses aménagements annexes sis au lieu-dit Le Roudier-Ouest, (section AM, parcelles 242p, 541p, 81, 80, 243p, $456,545,543 p, 455,463$.), une opération de diagnostic archéologique a été effectuée les 26 et 27 janvier 2006. Le projet du futur bâtiment prend place sur un terrain de $51780 \mathrm{~m}^{2}$. Le conducteur de ce projet est l'entreprise ISOA isolation.

2 Sur le plan archéologique, aucun site notable n'est localisé sur l'emprise du terrain objet de l'étude. En revanche, à l'occasion des opérations d'archéologie préventive liées à la construction de l'autoroute $\mathrm{A} 89$, les sondages réalisés à proximité de l'emprise indiquaient la présence potentielle dans le secteur de sites néolithiques et médiévaux, et dans une moindre mesure, paléolithiques, même si les données ainsi recueillies avaient permis de reconnaître des phénomènes de perturbations importants pour ces occupations anciennes.

3 Pour le Néolithique et le Moyen Âge au contraire, deux sites tout proches sur la commune de Saint-Astier, ont fait l'objet d'études plus approfondies :

4 - le site archéologique de «La Mouline - La Massoulie » qui a livré des indices forts d'une occupation paléolithique, néolithique, antique et médiévale ;

5 - l'occupation médiévale de "Jevah», caractérisée par des structures en creux et un bâtiment d'habitation fondé.

6 Ainsi, ce secteur est très sensible pour l'archéologie.

7 Quarante-huit sondages ont été réalisés sur l'emprise du projet, à l'aide d'une pelle mécanique à chenilles munit d'un godet de curage de $2 \mathrm{~m}$ de large. 


\section{structures archéologiques. Deux sondages ont permis la mise au jour de fosses} contemporaines. Enfin trois d'entre eux ont révélé des indices de site.

La première, à l'ouest du terrain prospecté, enfouie assez profondément sous d'épais niveaux de colluvion (environ $1,80 \mathrm{~m}$ ), consiste en un horizon de sable argileux. Elle se compose d'éléments lithiques en assez faible concentration spatiale. L'industrie est cependant homogène et date du paléolithique supérieur, sans qu'une attribution culturelle plus fine puisse être donnée avec assurance. Le mobilier lithique est dans l'ensemble de bonne qualité et assez frais.

Cependant, un doute persiste en ce qui concerne le contexte sédimentaire de cet indice de site. En effet, le niveau archéologique se situe au sommet d'un faciès d'argiles sableuses à galets épars dont on pense qu'il est issu de la remobilisation par solifluxion d'alluvions anciennes. Ainsi, la possibilité d'une dégradation par solifluxion d'une occupation préhistorique est à retenir car cette hypothèse s'accorde aussi bien avec les caractéristiques de la nappe de vestiges qu'avec le contexte sédimentaire du site.

Une autre hypothèse consiste à considérer que la faiblesse de répartition spatiale et de zone de concentration des pièces est due au fait que nous nous trouvons à la périphérie d'un site beaucoup plus important, où des concentrations de silex, voire des amas de débitage pourraient se trouver. Le centre de ce site éventuel doit être cherché plus à l'ouest, en dehors de l'emprise actuelle du terrain objet de notre étude.

13 La seconde, au nord ouest de la zone diagnostiquée, à 0,45 $\mathrm{m}$ de profondeur environ, consiste en une série de structures fossoyées (fosse indéterminée, silos, trous de poteau, etc.) datant de la fin du bas Moyen âge (fin $\mathrm{XV}^{\mathrm{e}}$ s. probablement). Aucune organisation précise de type fondation de bâti n'a été repérée. De plus, peu de mobilier céramique a été récolté. Enfin, ce site est difficilement comparable à ceux ayant livré des artefacts médiévaux dans le secteur (ceux-ci se calant chronologiquement avant le début de la guerre de Cent Ans).

RIMÉ Marc

\section{INDEX}

operation Expertise (EX)

Index chronologique : Moyen Âge*, Paléolithique supérieur, Préhistoire

Thèmes : céramique médiévale, colluvion, fosse, industrie lithique, silo, solifluxion, trou de poteau

Index géographique : Aquitaine, Dordogne (24), Saint-Astier 
AUTEURS

MARC RIMÉ

INRAP 